\title{
Correction to: Efficacy and Tolerability of a Medical Device Repairing Emollient Cream Associated with a Topical Corticosteroid in Adults with Atopic Dermatitis: An Open-label, Intra-individual Randomized Controlled Study
}

Ana Beatris Rossi · Adeline Bacquey · Thérèse Nocera •

Marie-Dominique Thouvenin

Published online: March 1, 2019

(C) The Author(s) 2019

Correction to: Dermatol Ther (Heidelb) (2018) 8:217-228

https://doi.org/10.1007/s13555-018-0228-3

In the original publication, the formulation of the corticosteroid cream used in the study, and is located in the 'Materials' subsection of the Methods was incorrectly added as ' $1 \%$ desonide' instead of ' $0.1 \%$ desonide'. The correct text should read as 'The TCS cream containing 0.1\% desonide (LOCAPRED ${ }^{\circledR}$ ) was from Pierre Fabre France (Castres, France).

The original article can be found online at https://doi. org/10.1007/s13555-018-0228-3.

A. B. Rossi · A. Bacquey · T. Nocera .

M.-D. Thouvenin ( $₫)$

Clinical Skin Research and Development Center, Pierre Fabre Dermo-Cosmétique, 2 Rue Viguerie, Hotel Dieu, Toulouse, France

e-mail: marie.dominique.thouvenin@pierre-

fabre.com

\section{A. B. Rossi · T. Nocera}

Department of Dermatology, University Hospital

Toulouse, 24, chemin de Pouvourville TSA, 31059

Toulouse CEDEX 9, France 